\title{
USO DE GEOTECNOLOGIAS NA LOCAÇÃO ESPACIAL DE TORRES PARA DETECÇÃO DE INCÊNDIOS FLORESTAIS NO SEMIÁRIDO NORDESTINO
}

\author{
Fellipe Ragner Vicente de Assis ${ }^{1}$, Izaque Francisco Candeia de Mendonça ${ }^{2}$, José Evanaldo Rangel da \\ Silva ${ }^{3}$ Joedla Rodrigues de Lima $^{4}$ \\ ${ }^{1}$ Eng. Florestal, Mestrando em Ciências Florestais, UFCG, Patos, PB, Brasil - fellipe.florestal@gmail.com \\ ${ }^{2}$ Eng. Florestal, Dr., Unidade Acadêmica de Engenharia Florestal, UFCG, Patos, PB, Brasil - izaquecandeia @ gmail.com.br \\ ${ }^{3}$ Eng. Florestal, Mestrando em Ciências Florestais, UFCG, Patos, PB, Brasil - naldoflorestal@ yahoo.com.br \\ ${ }^{4}$ Eng $^{\mathrm{a}}$. Agrícola, Dr ${ }^{\mathrm{a}}$., Unidade Acadêmica de Engenharia Florestal, UFCG, Patos, PB, Brasil - joedlalima@ yahoo.com.br
}

Recebido para publicação: 03/07/2013 - Aceito para publicação: 14/11/2013

\begin{abstract}
Resumo
A possibilidade de manipular um grande volume de informações faz do SIG uma ótima ferramenta para análises ambientais. O objetivo do estudo foi identificar locais ideais para implantação de torres de vigilância de incêndios florestais, avaliar a potencialidade do SIG utilizado e testar a eficiência da metodologia proposta em áreas de caatinga. O estudo foi realizado na microbacia do rio do Saco, Santa Luzia, PB, Brasil. Foram gerados mapas de declividade, uso da terra, orientação das encostas, altimetria, temperatura, precipitação e risco potencial de incêndios, sendo correlacionados com as cotas de maior altitude e a proximidade de estradas para alocação das torres. Os resultados mostraram que 5863,1 ha $(61,6 \%)$ da área possuem elevado risco de incêndio. A torre 1 (T1) proporcionou a maior visualização $(41,2 \%)$ das áreas de alto a extremo risco. Já a combinação de T1 + T5 proporcionou a maior visualização da área $(74,9 \%)$. Para o uso de uma torre, foi indicada a instalação de T1; para combinação entre torres, a melhor associação foi T1 + T5. A metodologia se mostrou aplicável em outras áreas com características fisiográficas semelhantes. As rotinas do Sistema de Informações Geográficas Idrisi (SIG Idrisi) foram capazes de atender satisfatoriamente aos procedimentos metodológicos utilizados.

Palavras-chave: Bacia hidrográfica; geoprocessamento; risco de incêndio.
\end{abstract}

\begin{abstract}
Use of geotechnology for towers placement in order to detect forest fires in northeastern Semiarid. The ability to handle a large volume of information makes GIS a great tool for environmental analysis. This research aims to identify ideal sites for installation of watchtowers forest fires, in order to evaluate the potential of SIG as well as to test efficiency of the proposed methodology in areas of Caatinga. The study was conducted in the watershed of the Saco River, Santa Luzia - PB, Brazil. We generated maps of slope, land use, orientation of slopes, altitude, temperature, precipitation and potential risk of fire, correlated with the dimensions of higher altitude and proximity of roads to towers installation. The results revealed that 5863.1 ha $(61.6 \%)$ of the area is at high fire risk. Tower 1 (T1) presented the better visualization $(41.2 \%)$ of areas of high to extreme risk. The combination of $\mathrm{T} 1+\mathrm{T} 5 \mathrm{had}$ as result better visualization of the area $(74.9 \%)$. For the use of one only tower, it was indicated $\mathrm{T} 1$, in relation to combination the best one was the association of $\mathrm{T} 1+\mathrm{T} 5$. The methodology proved its applicability in other areas with similar physiographic characteristics. Geographic Information System Idrisi (SIG Idrisi) routines were able to meet satisfactorily the methodological procedures.

Keywords: Watershed; geoprocessing; risk of fire.
\end{abstract}

\section{INTRODUÇÃO}

Os sistemas ambientais, especialmente aqueles mais fragilizados em seus aspectos físicos, químicos e biológicos, têm, ao longo das últimas décadas, recebido ações antrópicas consideráveis, que, associadas a causas naturais, vêm promovendo sérios riscos à manutenção da estabilidade cinética do 
meio. Intrinsecamente ligados a esses contextos, destacam-se os incêndios florestais, cuja ação afeta a estabilidade no processo de resiliência ambiental, promovendo, desse modo, sérios riscos à sustentabilidade do meio.

Vários fatores estão ligados diretamente à ocorrência de incêndios florestais, sendo as variáveis climáticas, o material combustível característico da área e o relevo os mais relevantes. Desse modo, surgem preocupações relativas à prevenção, principalmente de quem trabalha à frente de projetos de plantios comerciais e unidades de conservação (NOGUEIRA et al., 2002).

O semiárido do nordeste brasileiro caracteriza-se pela irregularidade na distribuição espacial e temporal das precipitações pluviométricas. Esse aspecto, associado às elevadas temperaturas registradas ao longo do ano e à prática da agricultura familiar intensiva, contribui sobremaneira para a ocorrência de incêndios florestais.

Em se tratando de detecção dos focos de incêndio, um método muito eficiente é o da utilização das torres de observação, que reduzem o tempo do primeiro combate (OLIVEIRA, 2002). Porém, como elas representam uma parte expressiva do orçamento de um sistema de controle, a sua implantação exige um planejamento cuidadoso, no sentido da utilização do menor número de torres para cobrir a maior área possível. Nesse sentido, os Sistemas de Informações Geográficas (SIG) constituem uma ótima ferramenta, por possibilitarem a combinação dos mais variados planos de informações, permitindo a associação ideal entre a quantidade necessária de torres e a área máxima de visualização (NOGUEIRA et al., 2002).

A área de estudo é a bacia hidrográfica do rio do Saco, localizada no município de Santa Luzia, $\mathrm{PB}$, ocupada por formação florestal tipo caatinga, portanto, áreas que se caracterizam por extrema fragilidade ambiental. Nesse particular, estudos que objetivem a locação espacial ótima na instalação de torres para vigilância de incêndios florestais como prática à mitigação de danos ambientais a esse ecossistema, constituem um procedimento importante para planificação do seu meio.

A exígua abordagem científica relativa ao tema no bioma caatinga reforça a necessidade da aplicação da metodologia na área de estudo. Nesse aspecto, Santana et al. (2011), em estudos desenvolvidos em área de caatinga com características fisiográficas similares à área deste estudo, analisam os perigos, sob o ponto de vista temporal, na Estação Ecológica do Seridó (EsEc-Seridó), em Serra Negra do Norte, RN, constatando que os meses correspondentes ao período de menores índices pluviométricos, compreendido entre os meses de agosto a novembro, apresentam maior potencial de perigo de incêndios florestais. Por outro lado, o interstício correspondente à quadra chuvosa, janeiro a abril, apresenta o menor índice de perigo. Os procedimentos metodológicos adotados para o combate de incêndios florestais desenvolvidos no presente estudo poderão ser aplicados em áreas de caatinga que apresentem similaridades físico-químicas e biológicas à deste estudo.

A pesquisa objetivou o emprego de geotecnologias à determinação de locais ideais para implantação de torres de observação contra incêndios florestais, além do número ótimo de torres a serem instaladas para alcançar maior visibilidade da área de estudo. Observou-se, outrossim, a funcionalidade do SIG Idrisi Andes v. 15.0 (EASTMAN, 2006) na otimização da metodologia proposta.

\section{MATERIAL E MÉTODOS}

A microbacia do rio do Saco localiza-se no município de Santa Luzia, PB, ao norte da região central do estado da Paraíba, mesorregião da Borborema e microrregião do Seridó Ocidental paraibano (Figura 1).

Situada hidrograficamente na bacia Piranhas-Açu, sub-bacia do rio Seridó, a microbacia do rio do Saco possui uma área de $95,1 \mathrm{~km}^{2}$, circunscrita às coordenadas geográficas $6^{\circ} 52$ '24" a $7^{\circ} 3^{\prime} 23^{\prime \prime}$ de latitude sul e $36^{\circ} 52^{\prime} 14^{\prime \prime}$ a $36^{\circ} 57^{\prime} 09^{\prime \prime}$ de longitude a oeste de Greenwich, sendo importante contribuinte do rio Quipauá, principal curso da drenagem do município de Santa Luzia, PB. O clima da área de estudo é do tipo BSh (tropical, quente seco, semiárido com chuvas de verão), segundo Köppen (1931). A pluviometria média anual é de 550,5 mm concentrados nos quatro primeiros meses do ano. A vegetação predominante é a caatinga hiperxerófila, do tipo arbustivo-arbórea aberta (MASCARENHAS et al., 2005; ALVES et al., 2011). 


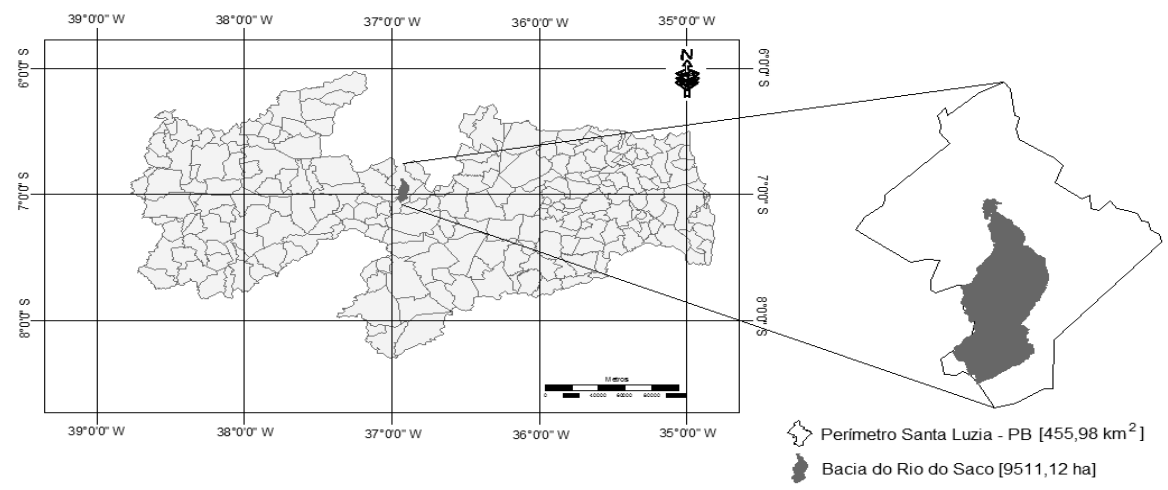

Figura 1. Mapa de localização do município de Santa Luzia, PB, e da microbacia hidrográfica do rio do Saco. Adaptado da Agência Executiva de Gestão das Águas do Estado da Paraíba (AESA, 2013).

Figure 1. Location map of the city of Santa Luzia, PB, and the watershed of the Saco river. Adapted of Executive Agency of Administration of the Waters of the State of Paraíba (AESA, 2013).

\section{Variáveis físicas de perigos de incêndios florestais}

As variáveis comumente consideradas na avaliação de riscos de incêndios florestais são aquelas que exercem forte influência na propagação do fogo, a saber: condições climáticas, tipo de cobertura vegetal e topografia (OLIVEIRA et al., 2004). Foram gerados planos de informações relativos a cobertura vegetal, declividade do terreno, orientação das encostas, altimetria e normais climatológicas de temperatura e precipitação adquiridas no Departamento de Ciências Atmosféricas/Universidade Federal de Campina Grande (DCA/UFCG, 2013).

\section{Declividade}

A análise da primeira variável considerada para determinação do perigo potencial à ocorrência de incêndios florestais deu-se através do estudo da declividade, sendo esta uma variável topográfica que ocasiona elevada propagação das chamas e direciona o sentido do fogo, facilitando a transferência de calor no sentido do aclive.

O mapa de declividade da área de estudo foi obtido a partir do Modelo Digital de Elevação (MDE) do projeto ASTER GDEM (Advanced Spaceborne Thermal Emission and Reflection Radiometer Global Digital Elevation Model), o qual foi integrado no software Idrisi v. 15.0 através do módulo GIS analysis > Surface Analysis > Topographic Variables > Slope. Após essa etapa, foi realizada uma reclassificação do mapa de declividade, para a obtenção de 5 classes de perigo de incêndios florestais, as quais variaram de baixo a extremo perigo de ocorrência.

$\mathrm{O}$ perigo de incêndios florestais em relação à declividade foi avaliado de acordo com a classificação adaptada por Soares (1985), que ordenou a declividade em 5 classes em percentagem (0-15, 15-25, 25-35, 35-45 e > 45) e atribuiu, para cada uma, coeficientes referentes ao perigo de incêndio (1baixo, 2-moderado, 3-alto, 4-muito alto e 5-extremo, respectivamente).

Uso da terra e cobertura vegetal

O plano de informações do uso atual da terra foi gerado a partir de uma classificação visual com base em elementos de reconhecimento (tonalidade, textura e forma), usando-se duas imagens do satélite ResourceSat, sensor "LIS3", órbita 337, ponto 081, bandas 2, 3 e 4, com datas de passagem em 21/04/2012 e 30/10/2012, 0 e 10\%, respectivamente, de cobertura de nuvens para a área de estudo. A partir das bandas espectrais utilizadas, foi gerada uma composição colorida 2B4G3R, para obtenção de uma melhor visualização e identificação dos alvos de interesses. A rotulação das tipologias de vegetação foi baseada em amostragem de campo.

Após a determinação do mapa de uso e identificação de cada tipologia presente na área de estudo, procedeu-se à distribuição em classes dos temas obtidos, de acordo com sua vulnerabilidade ao fogo, com atribuição dos coeficientes relativos ao nível de perigo de incêndio a que cada uma está sujeita. 
Para essa atribuição, foi adaptada para as condições da área de estudo a classificação utilizada por Oliveira et al. (2004), sendo esta utilizada como base para a elaboração do mapa de perigo de incêndio em relação à cobertura vegetal (Tabela 1).

Tabela 1. Classificação do perigo de incêndios florestais segundo o uso da terra e cobertura vegetal. Adaptado de Oliveira et al. (2004).

Table 1. Classification of forest fire risk according to the land use and plant cover. Adapted from Oliveira et al. (2004).

\begin{tabular}{lll}
\hline Uso da terra & Perigo & Coeficiente \\
\hline Afloramentos rochosos, exploração mineral e área degradada & Baixo & 1 \\
Caatinga arbustiva arbórea fechada (CAAF) e reflorestamento & Moderado & 2 \\
Culturas agrícolas e associações (culturas agrícolas + pastagens) & Alto & 3 \\
Caatinga arbustiva arbórea aberta & Muito alto & 4 \\
Pastagem (pasto nativo e campo sujo) & Extremo & 5 \\
\hline
\end{tabular}

Orientação das encostas

Com relação às faces de exposição à incidência solar (aspecto), outra variável de grande relevância na pesquisa, verificou-se que, segundo Venturi e Antunes (2007), o perigo de ocorrência de incêndios florestais é diretamente proporcional à maior exposição do relevo à incidência solar e, por conseguinte, ao aquecimento mais rápido do material combustível nesse inserto.

O plano de informações correspondente ao mapa de exposição foi gerado a partir do Modelo Digital do Terreno (MDT) do projeto ASTER GDEM (Advanced Spaceborne Thermal Emission and Reflection Radiometer Global Digital Elevation Model), com resolução espacial de 30 metros. Com a utilização do Idrisi v. 15.0, utilizou-se o módulo GIS analysis > Surface Analysis > Topographic Variables > Aspect, o qual gerou o mapa de aspecto. Este, por sua vez, foi reclassificado a partir do módulo Reclass, dando origem a 5 classes de faces de exposição à incidência solar.

A partir da classificação adaptada por Ferraz e Vettorazzi (1998) para o hemisfério Sul, foi determinado o perigo de incêndio para todas as faces de exposição e seus respectivos coeficientes: sudeste, sul e sudoeste (1-baixo risco); leste (2-moderado); nordeste (3-alto); noroeste e oeste (4-muito alto) e norte (5-extremo).

\section{Altimetria}

Soares e Batista (2004) afirmam que, a partir da superfície do solo, ocorre uma variação na temperatura do ar, responsável pela formação de um gradiente que determina a taxa de variação de temperatura, correlato à altitude. Os mesmos autores indicam um valor médio para esses processos adiabáticos, onde a cada 100 metros de altitude há uma redução na temperatura de $0,6^{\circ} \mathrm{C}$.

Para obter o mapa de altimetria, foram estabelecidas 5 classes hipsométricas a partir da amplitude altimétrica da área de estudo (253 a $353 \mathrm{~m}, 353$ a $453 \mathrm{~m}, 453$ a $553 \mathrm{~m}, 553$ a 653 e > $653 \mathrm{~m})$, aplicando-se para cada classe coeficientes de vulnerabilidade associados ao perigo potencial de ocorrência de incêndio florestal (5-extremo, 4-muito alto, 3-alto, 2-moderado e 1-baixo, respectivamente).

\section{Temperatura}

A maior suscetibilidade à ocorrência de incêndios florestais é diretamente proporcional à elevação da temperatura do ar, visto que essa condição resulta numa redução da umidade do material combustível.

Foram estabelecidas classes de perigo potencial de incêndios, como também seus respectivos coeficientes de suscetibilidade, a partir das temperaturas médias.

Para os dados de temperatura média do município de Santa Luzia, foram consideradas as médias mensais segundo a série histórica de 1950 a 2002 (DCA/UFCG, 2013). Para avaliação da influência dessa variável, o período foi divido em três épocas: 1 - janeiro a abril, 2 - maio a agosto e 3 - setembro a dezembro. Em seguida foi determinada a temperatura média para os três períodos estabelecidos, constatando-se que a média referente ao terceiro período (setembro a dezembro) apresentou maior temperatura média. Consequentemente, esse período apresenta maior potencial à ocorrência de incêndios florestais para a região de estudo. Sendo assim, foi gerado um mapa de temperatura média mensal para o 
período de maior perigo, sendo atribuídos pesos com base na média segundo a série histórica de cada mês (Tabela 2).

Tabela 2. Classificação do perigo de incêndios florestais segundo a média histórica de temperatura $\left({ }^{\circ} \mathrm{C}\right)$. Table 2. Classification of forest fire risk according to the historical average temperature $\left({ }^{\circ} \mathrm{C}\right)$.

\begin{tabular}{lccc}
\hline Meses & Média histórica de temperatura $\left({ }^{\circ} \mathbf{C}\right)$ & Perigo & Coeficiente \\
\hline Setembro & 23,40 & Baixo & 1 \\
Outubro & 24,15 & Moderado & 2 \\
Novembro & 24,54 & Alto & 3 \\
Dezembro & 24,82 & Extremo & 4 \\
\hline
\end{tabular}

Precipitação

A precipitação tem influência direta na composição das variáveis e consequentemente no perigo de incêndios florestais, sendo que quanto maior a precipitação maior será a umidade do material combustível, reduzindo assim a ocorrência de incêndios.

Foram estabelecidas classes de perigo potencial de incêndios, como também seus respectivos coeficientes de suscetibilidade, a partir da precipitação média da área de estudo (Tabela 3).

Tabela 3. Classificação do perigo de incêndios florestais segundo média histórica de precipitação (mm). Table 3. Classification of the risk of forest fires according of historical average rainfall (mm).

\begin{tabular}{lccc}
\hline Meses & Média histórica de precipitação $\mathbf{( m m})$ & Perigo & Coeficiente \\
\hline Setembro & 1,40 & Extremo & 4 \\
Outubro & 3,50 & Alto & 3 \\
Novembro & 8,50 & Moderado & 2 \\
Dezembro & 21,20 & Baixo & 1 \\
\hline
\end{tabular}

Para os dados de precipitação média do município de Santa Luzia, foram consideradas as médias mensais segundo a série histórica de 1911 a 1990 (DCA/UFCG, 2013). A metodologia utilizada para essa variável seguiu a estabelecida para temperatura, determinando-se o período que apresentou precipitações médias mais baixas. O período mais crítico se concentrou nos meses de setembro a dezembro, revelandose como o de maior potencial à ocorrência de incêndios florestais. Sendo assim, foi gerado um mapa de precipitação média mensal para o período de maior perigo, sendo atribuídos pesos com base na média segundo a série histórica de cada mês.

\section{Mapa de perigo}

Para geração do mapa de perigo de incêndios, foram integradas todas as variáveis contextualizadas, a partir dos seus respectivos planos de informações, sendo variáveis associadas à topografia (declividade, orientação das encostas e altimetria), à vegetação (cobertura vegetal) e à climatologia (temperatura e precipitação).

Foi realizada a integração das variáveis, a partir de um modelo de ponderação adaptado de Prudente (2010), que indica os seus níveis de influência na ocorrência de incêndios florestais.

$$
\text { PERIGO }=30 \mathrm{U}+15 \mathrm{~T}+25 \mathrm{P}+10 \mathrm{D}+10 \mathrm{~A}+10 \mathrm{E}
$$

Em que: $\mathrm{U}=$ coeficiente de risco de incêndios florestais segundo o uso da terra;

$\mathrm{T}=$ coeficiente de risco de incêndios florestais segundo a temperatura;

$\mathrm{P}=$ coeficiente de risco de incêndios florestais segundo a precipitação;

$\mathrm{D}=$ coeficiente de risco de incêndios florestais segundo a declividade;

$\mathrm{A}=$ coeficiente de risco de incêndios florestais segundo a altimetria;

$\mathrm{E}=$ coeficiente de risco de incêndios florestais segundo a orientação das encostas.

O mapa de perigo de incêndios florestais foi gerado a partir do módulo GIS analysis > Database Query > Image Calculator do Idrisi, o qual integra a soma de todas as variáveis e seus respectivos pesos 
atribuídos. Os valores obtidos pelo somatório dos mapas-base variaram entre 175 a 405 . Com isso, o mapa de perigo de incêndios florestais foi reclassificado para delimitar 5 classes potenciais à ocorrência de incêndios, a partir da amplitude calculada, sendo: 1-baixo risco (175 a 221); 2-moderado (221 a 267); 3-alto (267 a 313); 4-muito alto (313 a 359); 5-extremo (359 a 405).

\section{Critérios para escolha do local de instalação das torres}

A instalação de torres de vigilância de incêndios florestais tem como principal objetivo indicar que as áreas de maior perigo de ocorrência de incêndios tenham uma observação mais detalhada e cuidadosa. De acordo com Soares (1985), atender a totalidade de observação da área de estudo a partir da visibilidade das torres é praticamente impossível. Sendo assim, o mesmo autor estima que o alcance de 70 a $80 \%$ de visibilidade da área de interesse já pode ser considerado um percentual satisfatório.

A determinação dos locais ideais para instalação das torres de vigilância de incêndios florestais decorreu da análise de três fatores: 1) proximidade das áreas que apresentaram maior perigo à ocorrência de incêndios florestais; 2) cotas de maior altitude, que promovem uma maior área de observação; 3) proximidade de estradas. A partir dessas três variáveis, foram determinados os locais potenciais à instalação das torres, gerando-se um arquivo vetorial de pontos, convertido em formato matricial sobre a máscara da bacia. Em seguida, empregou-se o módulo GIS analysis > Context Operators $>$ Viewshed do Idrisi, para integrar o modelo digital do terreno com os pontos dos possíveis locais de instalação das torres.

Após esses procedimentos, foi avaliada a percentagem de visibilidade de cada torre. Caso a área de visibilidade das torres não fosse satisfatória, seriam determinados novos locais para avaliação de visibilidade da área de estudo. Do contrário, atendendo a metodologia proposta para a visibilidade (VENTURI; ANTUNES, 2007), gera-se o mapa que indica a espacialização das torres de vigilância de incêndios florestais.

Por fim, através do módulo GIS Analysis > Database Query > Overlay do Idrisi, foi obtida a sobreposição da área de visibilidade entre torres, para avaliar o uso de mais de uma torre na área de estudo, através da verificação do ganho em visibilidade proporcionado pelas combinações, como preconizado por Venturi e Antunes (2007).

\section{RESULTADOS E DISCUSSÃO}

\section{Modelo digital do terreno (MDT)}

A bacia do rio do Saco apresenta ampla diferença hipsométrica, que varia de 253 a 826 metros de altitude, com uma parte plana na sua face norte, que se estende do açude de Santa Luzia até a parte central da bacia, onde o terreno começa a se elevar de forma rápida, atingindo o máximo de altitude no seu extremo sul, na Serra do Pinga.

\section{Variáveis físicas de perigo de incêndios florestais}

Os mapas com as variáveis declividade, altimetria, orientação das encostas e uso da terra estão presentes na figura 2. Inicialmente, avaliou-se a participação dessas variáveis isoladamente, e depois em conjunto no perigo de propagação dos incêndios florestais, gerando-se o mapa de perigo potencial a partir da soma das mesmas com as médias, segundo as séries históricas, de temperatura e precipitação.

Em relação à área de influência da bacia do rio do Saco, a declividade até 15\% (Figura 2A) foi a classe que apresentou maior área $(6668,5 \mathrm{ha})$, sendo assim caracterizada como de baixo perigo de incêndio segundo a declividade, já que nessas áreas o fogo apresenta baixa propagação de chamas, devido ao relevo mais plano. Porém na bacia também existe uma área significativa $(383,9$ ha), com declividade acima de $45 \%$, que, por ter relevo ondulado, é considerada como de perigo extremo de incêndio.

A temperatura do ar é uma variável que está inversamente correlacionada com a altimetria. Locais de menor altitude apresentam os maiores perigos de incêndios. Por esse critério, a área de estudo possui 3404,7 ha com perigo extremo de incêndios (Figura 2B), 1228,4 ha de perigo muito alto e 1540,2 ha de perigo alto.

Para o mapa de aspecto, foram determinadas 5 classes de perigo (Figura 2C), nas quais predominaram as áreas com exposição NW/W (3318,9 ha) e N (1534,2 ha), ou seja, áreas com maior 
suscetibilidade aos incêndios, devido ao maior tempo de exposição à radiação solar, gerando aquecimento e perigo de ignição.

Com a determinação do mapa de uso da terra (Figura 2D), observa-se que 527,3 ha possuem baixo perigo de ocorrência de incêndios florestais. Por sua vez, as áreas com extremo, alto e moderado perigo apresentaram os seguintes valores: 1435,0 ha, 3291,0 ha e 323,9 ha, respectivamente. Para os perigos de incêndios com coeficientes 4 e 5, referentes à caatinga arbustiva arbórea aberta e pastagem, respectivamente, tomaram-se essas tipologias como fundamentais na propagação de incêndio, uma vez que tanto o pasto nativo quanto a vegetação aberta possuem elementos em sua composição que potencializam o perigo de incêndios.
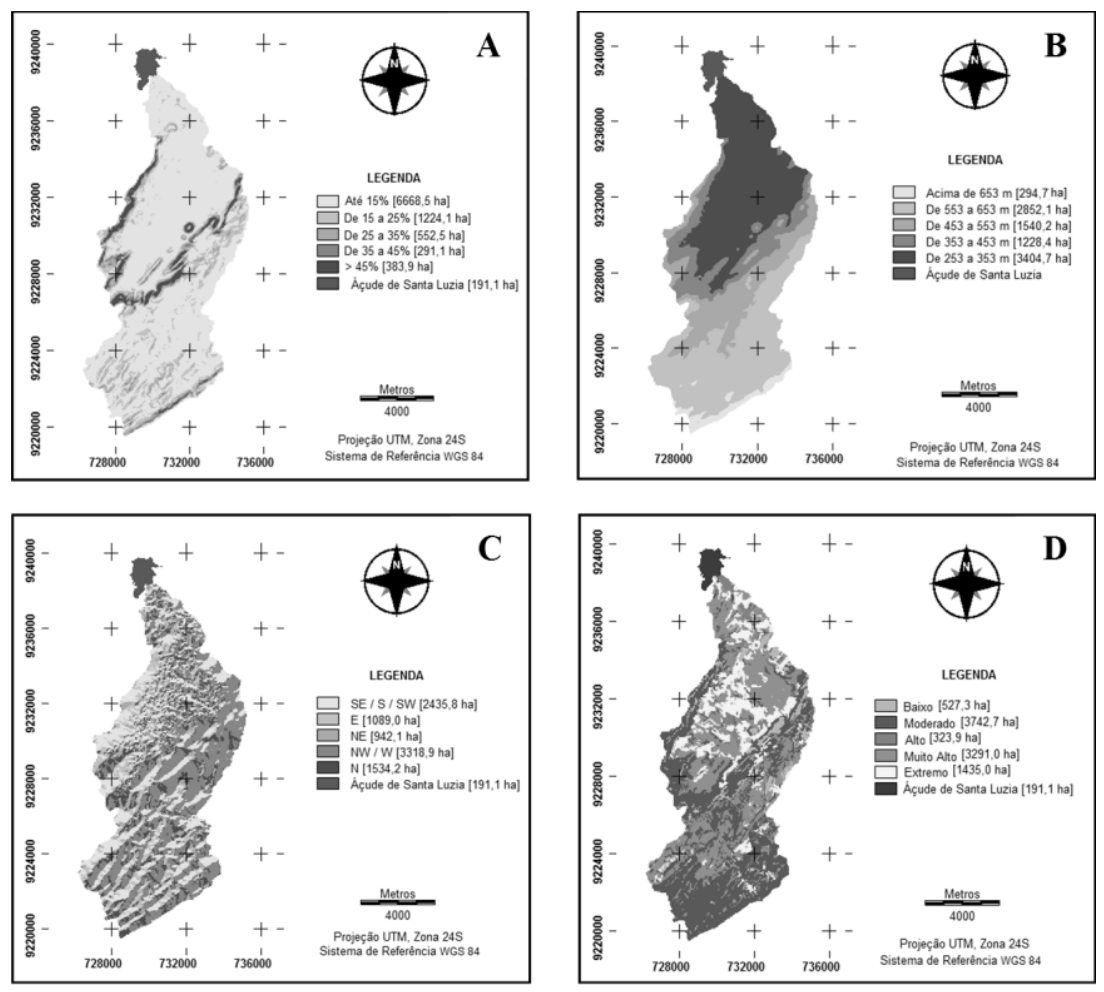

Figura 2. Mapas referentes às seguintes variáveis físicas de perigo de incêndios florestais da microbacia hidrográfica do rio do Saco: (A) declividade, (B) altimetria, (C) aspecto das encostas e (D) perigo segundo o uso da terra.

Figure 2. Referents maps of physical variables in the risk of forest fires in the watershed of the Saco river: (A) slope, (B) altimetry (C) aspect of the slopes and (D) risk according to land use.

Temperatura e precipitação

As temperaturas médias da área de estudo não apresentam uma grande amplitude térmica, observando-se que nos meses de maio a agosto é registrada a média mais baixa de $22,51^{\circ} \mathrm{C}$. Ressalta-se que as médias anuais estão abaixo daquelas registradas em outras regiões da depressão sertaneja, tendo em vista a inserção dessa área em porções de relevo mais elevados.

Foi observado que o período de setembro a dezembro apresentou as maiores médias térmicas, sendo que a variação entre esses meses aponta dezembro como o mês que apresenta a maior média de temperatura.

O período em que se verificaram as maiores médias de precipitação corresponde à quadra chuvosa de janeiro a abril, sendo que nos demais meses são verificados baixos índices de precipitação, correspondendo ao que se verifica em toda a região semiárida do Nordeste brasileiro.

Com relação à avaliação do perigo de incêndios considerando a precipitação, foi determinado o período de setembro a dezembro como o mais suscetível, por proporcionar as médias mais baixas de 
precipitação $(8,65 \mathrm{~mm})$, tendo em vista que nesse período o material combustível está com baixa umidade, aumentando assim o perigo potencial à ocorrência de incêndios. Como o mês de setembro apresentou menor média de precipitação, ele foi escolhido para a determinação do mapa de perigo de incêndio.

\section{Mapa de perigo de incêndios florestais e locação espacial das torres}

A partir da ponderação dos pesos das variáveis envolvidas no perigo de ocorrência de incêndios (declividade, altimetria, aspecto, uso do solo, temperatura e precipitação), foram obtidos valores de coeficiente que variaram de 175 a 405, sendo que, a partir da amplitude encontrada, procedeu-se à distribuição dos pesos em 5 classes e posterior montagem do mapa de perigo de incêndios (Figura 3A) e escolha dos locais potenciais para alocação das torres (Figura 3B).
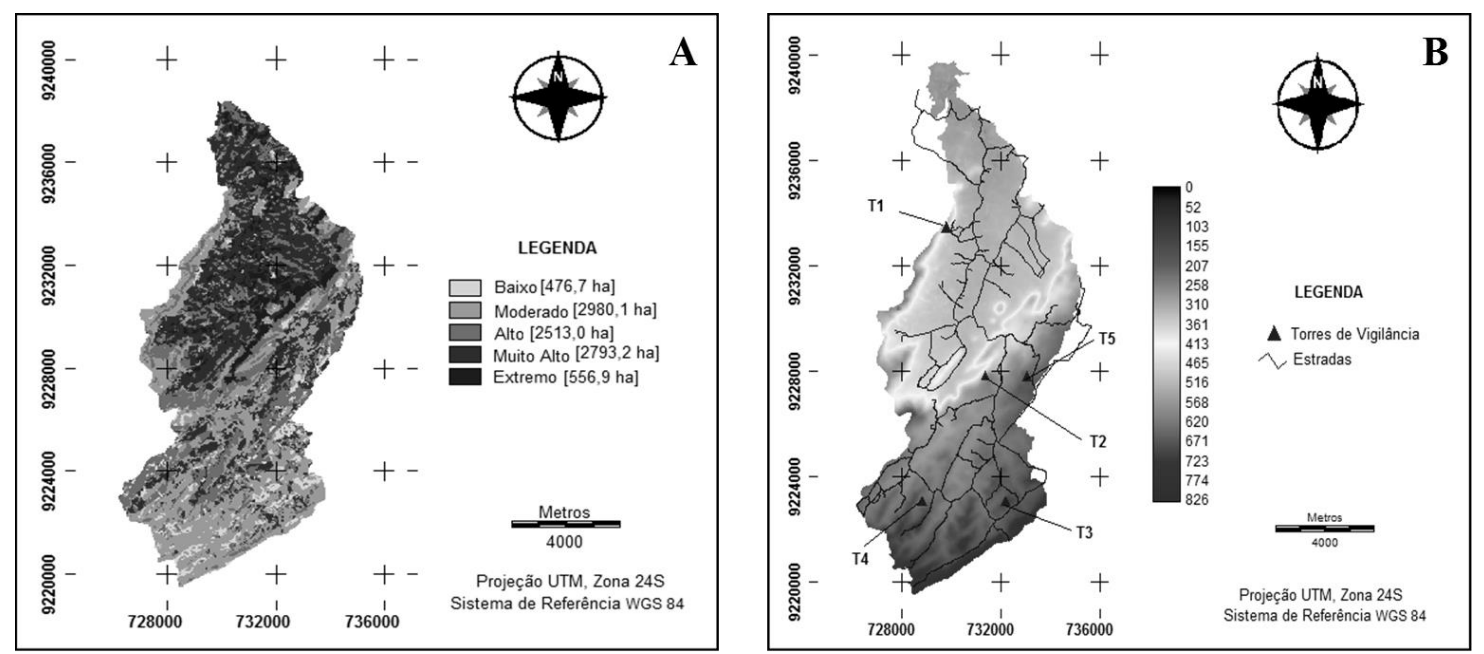

Figura 3. Mapa de perigo de incêndios florestais (A) e de localização espacial de torres para controle de incêndios florestais (B) na microbacia do rio do Saco, município de Santa Luzia, PB.

Figure 3. Map of forest fire risk (A) and space location of towers to control forest fire (B) in the watershed of the Saco river, municipality of Santa Luzia, PB.

Os dados mostram que as três classes de maior perigo de ocorrência de incêndios (alta, muito alta e extremo perigo), quando somadas suas áreas de abrangência, totalizam 5863,1 ha (61,64\%). Esses valores caracterizam um elevado potencial de perigo de incêndio para a bacia hidrográfica. Dessa forma, fica evidente a necessidade de se ter a atenção voltada à fiscalização, principalmente nessas áreas de maior potencialidade à ocorrência de incêndios florestais.

Foram escolhidos cinco locais potenciais à instalação das torres (Figura 3B), a partir da proximidade de estradas, das áreas com maior potencial de perigo de incêndios florestais e que apresentassem cotas altimétrica que proporcionassem uma maior visualização de toda a área.

Determinados os locais de instalação preliminar das torres, procedeu-se à avaliação da visibilidade da área de estudo, levando em consideração a visibilidade individual de cada torre, assim como a sua combinação aos pares.

No caso das torres individualmente (Figura 4A), a torre 2 (T2) proporcionou maior visibilidade da área total, correspondendo a 5405,4 ha (56,8\%), seguida da torre 1 (T1), com área de visibilidade de 5225,2 ha $(54,9 \%)$. Porém, quando analisadas as áreas de visibilidade das duas torres correspondente a cada perigo, constatou-se que T1 proporciona, quando somadas as áreas de perigo alto, muito alto e extremo, a visualização de 3915,6 ha $(41,2 \%)$ em relação à área total da bacia hidrográfica. Já com a torre 2 (T2) é possível visualizar 3538,4 ha (37,2\%), o que indica que para a instalação de uma única torre de vigilância contra incêndios na área de estudo, T2 apresentou maior visibilidade em relação à área total, enquanto que T1 proporcionou maior área visível de suscetibilidade à ocorrência de incêndios. 

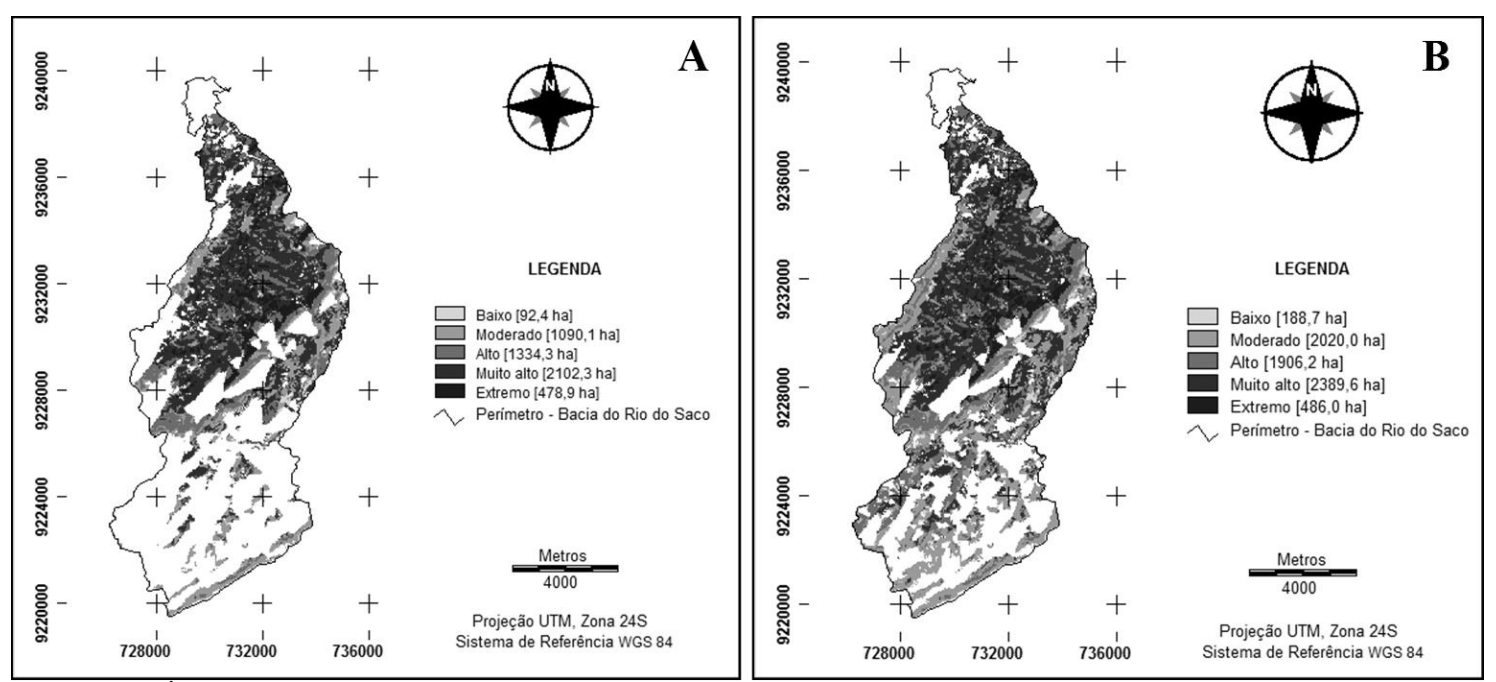

Figura 4. Áreas de perigo potencial de incêndios visualizadas com a implantação das torres T1 (A) e T1 + T5 (B) na microbacia do rio do Saco, município de Santa Luzia, PB.

Figure 4. Potential risk areas of fires visualized by deploying towers T1 (A) and T1 + T5 (B) in the watershed of the Saco river, municipality of Santa Luzia, PB.

Assim, visto que a visibilidade de área total de cada uma das duas torres (T1 e T2) é muito próxima uma da outra e que se pretendeu atender à locação das torres em pontos que possibilitassem maior visualização das áreas com perigo de incêndios mais elevados, a melhor escolha para a área de estudo é a torre 1 (T1). Esta, por sua vez, não atendeu à percentagem de área visível proposta por Soares (1985), que é de 70 a $80 \%$, mas se torna possível a implantação somente da T1 considerando que as demais áreas podem ser patrulhadas de outras formas (veículos motorizados, animais de montaria e/ou a pé).

Testando a combinação de implantação de duas torres (Figura 4B), foi constatado que a maior área de visibilidade alcançada se deu entre as torres 1 e 5 (T1 e T5), com visibilidade de 7123,4 ha (74,9\%), seguida da combinação entre as torres 1 e 2 (T1 e T2), com área de visibilidade de 7025,5 ha (73,9\%), quando somadas as áreas de perigo alto, muito alto e extremo, em relação à área da bacia hidrográfica. Isso indica ganho de 1\% de área visível de T1/T5 quando comparada a T1/T2.

Com relação à visibilidade das áreas de alto a extremo perigo, praticamente não houve diferença de área de visualização entre as duas combinações de torres (T1/T5 e T1/T2), com 4781,8 ha (50,3\%) e 4799,1 ha $(50,5 \%)$, respectivamente, havendo apenas um incremento de $0,2 \%$ em visibilidade de T1/T2 quando comparada a T1/T5. Nesse caso, visto que a área de perigo visualizada por cada combinação variou pouco $(0,2 \%)$ em relação à área de visibilidade total $(1 \%)$, determinou-se como melhor escolha as torres 1 e 5 (T1 e T5) (Figura 4B).

Dessa forma, a instalação de uma segunda torre (T5), nesse caso combinada com a torre já escolhida (T1), proporcionaria um ganho de $20 \%$ na visibilidade total da área de estudo, o que é justificável caso a área adicional apresente alta importância ecológica, econômica e/ou social, como observado por Nogueira et al. (2002).

\section{CONCLUSÕES}

- A partir da metodologia proposta, obteve-se êxito na determinação dos locais ideais para instalação de torres de vigilância de incêndios florestais, sendo indicada a instalação da torre 1, adotando-se para as demais áreas patrulhamento motorizado, em montaria ou a pé.

- No caso de se usarem duas torres, a melhor combinação foi entre as torres 1 e 5, em que o acréscimo de $\mathrm{T} 5$ proporcionou um ganho de $20 \%$ de área total. 
- A metodologia empregada no presente estudo atendeu satisfatoriamente aos objetivos propostos, permitindo a indicação dos procedimentos metodológicos adotados em outras áreas da região semiárida do Nordeste brasileiro, cujas características fisiográficas se assemelham à da área avaliada nesta pesquisa.

- A utilização do SIG mostrou-se satisfatória, conferindo rapidez e precisão a todos os procedimentos requeridos no trabalho, o que mostra a importância do uso de geotecnologias na análise, planejamento e tomada de decisões em questões ambientais.

\section{REFERÊNCIAS}

Agência Executiva de Gestão das Águas do Estado da Paraíba (AESA). Mapas do Plano Estadual de Recursos Hídricos. Disponível em: 〈http://www.aesa.pb.gov.br/geoprocessamento/geoportal/shapes.html>. Acesso em: 13/01/2013.

ALVES, T. L. B.; ARAÚJO, A. R.; ALVES, A. N.; FERREIRA, A. C.; NÓBREGA, J. E. da. Diagnóstico ambiental da microbacia hidrográfica do rio do Saco, Santa Luzia, PB. Revista Brasileira de Geografia Física, v. 4, n. 2, p. 396 - 412. 2011.

Departamento de Ciências Atmosféricas/Universidade Federal de Campina Grande (DCA/UFCG). Dados climatológicos do Estado da Paraíba. Disponível em: 〈http://www.dca.ufcg.edu.br/clima/dadospb.htm〉. Acesso em: 05/02/2013.

EASTMAN, J. R. Idrisi Andes: Tutorial version 15.00. Worcester: Clark University, 2006. 283 p.

FERRAZ, S. F. B.; VETTORAZZI, C. A. Mapeamento de risco de incêndios florestais por meio de sistema de informações geográficas (SIG). Scientia Forestalis, Piracicaba, v. 53, p. 39 - 48, 1998.

KÖPPEN, W. Grundriss der Klimakunde. Berlin: Walter de Gruyter, 1931. 390 p.

MASCARENHAS, J. C.; BELTRÃO, B. A.; SOUZA JÚNIOR, L. C.; MORAIS, F.; MENDES, V. A.; MIRANDA, J. L. F. Projeto cadastro de fontes de abastecimento por água subterrânea: Diagnóstico do município de Santa Luzia, estado da Paraíba. Recife: CPRM/PRODEEM, 10 p. 2005.

NOGUEIRA, G. S.; RIBEIRO, G. A.; RIBEIRO, C. A. A. S.; SILVA, E. P. Escolha de locais para instalação de torres de detecção de incêndio com auxílio do SIG. Revista Árvore, Viçosa, v. 26, n. 3, p. $363-369,2002$.

OLIVEIRA, D. S. Zoneamento de risco de incêndios em povoamentos florestais no norte de Santa Catarina. 113 f. Dissertação (Mestrado em Engenharia Florestal) - Universidade Federal do Paraná, Curitiba, 2002.

OLIVEIRA, D. S.; BATISTA, A. C.; SOARES, R. V.; GRODZKI, L.; VOSGERAU, J. Zoneamento de risco de incêndios florestais para o estado do Paraná. Floresta, Curitiba, v. 34, n. 2, p. 217 - 221, 2004.

PRUDENTE, T. D. Geotecnologias aplicadas ao mapeamento de risco de incêndio florestal no Parque Nacional da Chapada dos Veadeiros e área de entorno. 114 f. Dissertação (Mestrado em Geografia) - Universidade Federal de Uberlândia, Uberlândia, 2010.

SANTANA, J. A. S.; ARAÚJO, I. M. M.; SENA, C. M.; PIMENTA, A. S.; FONSECA, F. C. E. Determinação dos períodos críticos de ocorrência de incêndios florestais na estação ecológica do Seridó, Serra Negra do Norte, RN. Revista Caatinga, Mossoró, v. 24, n. 1, p. 43 - 47, 2011.

SOARES, R. V. Incêndios florestais: controle e uso do fogo. Curitiba: Fundação de Pesquisa Florestal do Paraná, 1985. 213 p.

SOARES, R. V.; BATISTA, A. C. Meteorologia e climatologia florestal. Curitiba: Editor, 2004. 195 p.

VENTURI, N. L.; ANTUNES, A. F. B. Determinação de locais ótimos para implantação de torres de vigilância para detecção de incêndios florestais por meio de sistema de informações geográficas. Floresta, Curitiba, v. 37, n. 2, p. 159 - 173, 2007. 